\title{
The voluntary feed intake of pigs given feeds based on wheat bran, dried citrus pulp and grass meal, in relation to measurements of feed bulk
}

\author{
BY I. KYRIAZAKIS AND G. C. EMMANS \\ Genetics and Behavioural Sciences Department, Scottish Agricultural College Edinburgh, \\ West Mains Road, Edinburgh EH9 3JG
}

(Received 11 November 1993 - Revised 31 May 1994 - Accepted 7 June 1994)

\begin{abstract}
Two experiments were carried out to investigate the capacities of pigs for bulky feeds. In Expt 1 fifteen pigs were offered, from 12 to $25 \mathrm{~kg}$ live weight, ad lib. access to one of five feeds which were made by progressively diluting a high-quality feed with wheat bran. Intake initially increased, and then declined, as the proportion of wheat bran was increased. The pigs became better able to accommodate to the more bulky feeds over time. In Expt 2 thirty-six pigs, initially of $12 \mathrm{~kg}$ live weight, were used. The feeds were the same high-quality basal feed as in Expt 1 and three others made almost entirely of either wheat bran, dried grass or dried citrus pulp, respectively. The equal-parts mixtures of each of these three bulky feeds with the basal feed were also made to give three series of feeds each comprising the basal, the mixture and the bulky feed. The three feeds in each series were given $a d$ lib. to twelve pigs in a design of two replicated Latin squares with three time-periods. Within each series, and across periods, the intakes of the feeds that were limiting intake were directly proportional to live weight and so a scaled intake, expressed as $\mathrm{g} / \mathrm{kg}$ live weight per $\mathrm{d}$, was calculated. Across the six limiting feeds, scaled intakes in the final $5 \mathrm{~d}$ of each period, when the pigs were in equilibrium with their feeds, were directly proportional to the reciprocal of the water-holding capacities (WHC) of the feeds, as measured by a centrifugation method. There were large effects of feed changes on intake, in the short term, with previous experience of a bulky feed leading to higher intakes of another bulky feed. The intake of the basal feed was not affected by the feed given previously. It was concluded that: (a) the time of adaptation to bulky feeds needs to be considered when attempting to measure, or predict, the rates of intake on different bulky feeds and, (b) the WHC of the feeds could be an appropriate measurement of 'bulk' responsible for limiting their intake, and could be used to predict the maximum feed intake capacity of pigs on different bulky feeds.
\end{abstract}

Feed intake: Gastrointestinal tract: Pigs: Water-holding capacity: Wheat bran

When a highly digestible feed is progressively diluted with one of greater 'bulk' the prevailing view is that (1) the rate of feed intake will initially increase at a rate such that digestible energy (DE) intake remains roughly constant and performance is unaffected and, (2) that, beyond a critical point, intake of feed and DE will fall and performance be reduced as the dilution proceeds further. The critical point has been assumed to reflect the capacity of the animal for 'bulk'. Examples are Mraz et al. (1957) for chickens, Conrad et al. (1964) for dairy cows and Owen \& Ridgman (1967) for pigs.

Lehmann (1941), on the basis of data from growing cattle, proposed that a suitable scale for bulk would be undigested dry matter. Current models which attempt to predict the voluntary feed intake of pigs use dry matter of the feed as a measure of bulk (e.g. Whittemore, 1983) or, following Lehmann (1941), the undigested organic matter (e.g. Roan, 1991), or ignore the problem (e.g. Agricultural Research Council, 1981). 
It was long been known, however, that such views are likely to be inadequate across the complete range of feeds. The dry matter from different feeds certainly has different filling effects (for chickens Mraz et al. 1957, for rats Peterson \& Baumgardt, 1971) and it is possible that the undigested dry, or organic, matter of different feeds may also have different bulk equivalents. More recently Brouns et al. (1991) found that the voluntary feed intake of sows was depressed far more by feeds based on sugar-beet pulp than by others based on more indigestible materials such as straw and rice bran.

It was thought to be likely, therefore, that some property other than the indigestibility of feeds of lower energy content could be responsible for the reduction in intake of such feeds in growing pigs. In view of the importance of being able to deal properly with such feeds in any general growth model (for example, see Emmans \& Fisher, 1986), it seemed proper to approach the problem experimentally. The experiments were designed with three purposes in mind: (1) to identify a property of 'bulky' feeds which might be responsible for limiting their intake, (2) to describe how the capacity for bulk varied with live weight of pigs and (3) to examine the extent to which the capacity for a bulky feed might be modified by previous experience. A possible scheme for dealing quantitatively with the effects of bulky feeds on intake is given in the Appendix.

\section{MATERIALS AND METHODS}

\section{Animals and housing}

Fifty-one Cotswold $F 1$ hybrid Large White $\times$ Landrace entire male pigs from thirteen litters were moved (in batches of forty and eleven) immediately after weaning into the individual cages of the experimental unit. The weaned pigs had a mean live weight of 7.4 (SD 1.3) $\mathrm{kg}$ and were given free and continuous access to a high-quality commercial feed (Earlycare 404 - BOCM Silcock). The pigs were used in the two contemporary experiments described later (p. 195).

The experimental unit consisted of two identical controlled-environment rooms separated by a central working area. Each room had its own heating, lighting and ventilation system, with a water supply serving two opposing ranks of the individual cages. Each cage contained one metal trough and a nipple drinker which gave free and continuous access to water. Underneath each trough a metal tray was placed, where feed spillage was collected.

\section{Feeds}

A basal feed (B) with 13.7 MJ DE and $234 \mathrm{~g}$ crude protein $(\mathrm{N} \times 6.25 ; \mathrm{CP}) / \mathrm{kg}$ fresh feed, and three 'bulky' feeds based on wheat bran (W) dried-grass meal $(\mathrm{G})$ and dried citrus pulp (C) were formulated. The bulky feeds were supplemented with synthetic amino acids and minerals in order to maintain similar ratios of synthetic amino acids:DE and minerals:DE and of protein:DE as in the basal feed.

The following mixtures between the basal and the bulky feeds were also made: the three 'step' mixtures between feeds $B$ and $W$ to produce feeds called $B W_{1}=(0.75 \mathrm{~B}+0.25 \mathrm{~W})$, $\mathrm{BW}_{2}=(0.5 \mathrm{~B}+0.5 \mathrm{~W})$ and $\mathrm{BW}_{3}=(0.25 \mathrm{~B}+0.75 \mathrm{~W})$; equal parts mixtures of $\mathrm{B}$ and feeds $\mathrm{G}$ and $\mathrm{C}$ to produce feeds $\mathrm{BG}_{2}=(0.5 \mathrm{~B}+0.5 \mathrm{G})$ and $\mathrm{BC}_{2}=(0.5 \mathrm{~B}+0.5 \mathrm{C})$ respectively. The compositions and the chemical analyses of the five feeds based on the $\mathrm{W}$ series are shown in Table 1, and those of the feeds based on $G$ and $C$ in Table 2. All feeds were pelleted.

Various measurements of the 'bulkiness' of the nine feeds used were made. These included measurement of the crude fibre (CF) and neutral-detergent fibre (NDF; Van Soest, 1963) contents, digestibility of the organic matter, density and water-holding capacity (WHC). The density of the feeds was measured according to the water- 
Table 1. The composition, chemical analysis ( $\mathrm{g} / \mathrm{kg}$ fresh weight) and 'bulk' characteristics of the basal diet $(B)$-wheat-bran $(W)$ series of feeds

\begin{tabular}{|c|c|c|c|c|c|}
\hline Feed ... & B & $\begin{array}{c}\mathrm{BW}_{1} \\
(0.75 \mathrm{~B}+0.25 \mathrm{~W})\end{array}$ & $\begin{array}{c}\mathrm{BW}_{2} \\
(0.5 \mathrm{~B}+0.5 \mathrm{~W})\end{array}$ & $\begin{array}{c}\mathrm{BW}_{3} \\
(0.25 \mathrm{~B}+0.75 \mathrm{~W})\end{array}$ & $\mathbf{w}$ \\
\hline \multicolumn{6}{|l|}{ Ingredients (g/kg) } \\
\hline Herring meal & 180 & 135 & 90 & 45 & - \\
\hline Dried skimmed milk & 100 & 75 & 50 & 25 & - \\
\hline Micronized wheat & 680 & 510 & 340 & 170 & - \\
\hline Wheat-bran & - & $242 \cdot 3$ & 484.7 & 727 & $969 \cdot 3$ \\
\hline Maize oil & 20 & 15 & 10 & 5 & - \\
\hline Lysine hydrochloride & - & 1.2 & $2 \cdot 3$ & $3 \cdot 5$ & 4.6 \\
\hline DL-Methionine & - & 0.6 & $1 \cdot 1$ & 1.7 & $2 \cdot 2$ \\
\hline L-Threonine & - & 0.2 & 0.5 & 0.7 & 0.9 \\
\hline Limestone & - & 0.6 & $1 \cdot 1$ & 1.7 & $2 \cdot 2$ \\
\hline Salt & - & 0.2 & 0.4 & 0.6 & 0.8 \\
\hline $\begin{array}{l}\text { Vitamin and mineral } \\
\text { supplement }\end{array}$ & 20 & 20 & 20 & 20 & 20 \\
\hline Total & $1000 \cdot 0$ & $1000 \cdot 1$ & $1000 \cdot 1$ & $1000 \cdot 2$ & $1000 \cdot 0$ \\
\hline \multicolumn{6}{|l|}{ Component (g/kg) } \\
\hline $\begin{array}{l}\text { Digestible energy } \\
(\mathrm{MJ} / \mathrm{kg})\end{array}$ & $13 \cdot 7$ & $12 \cdot 5$ & $11 \cdot 2$ & $10 \cdot 0$ & 8.7 \\
\hline Dry matter & 884 & 882 & 880 & 876 & 876 \\
\hline Crude protein $(\mathrm{N} \times 6.25)$ & 234 & 224 & 201 & 188 & 166 \\
\hline Diethyl ether extract & 53 & 49 & 40 & 35 & 41 \\
\hline Ash & 56 & 60 & 61 & 66 & 74 \\
\hline Crude fibre & 19 & 38 & 51 & 74 & 84 \\
\hline NDF & 86 & 163 & 249 & 325 & 397 \\
\hline Organic matter digestibility & 868 & nd & 718 & nd & 567 \\
\hline Density $(\mathrm{g} / \mathrm{ml})$ & 1.363 & $1 \cdot 350$ & $1 \cdot 321$ & 1.309 & 1.296 \\
\hline \multicolumn{6}{|l|}{$\begin{array}{l}\text { Water-holding capacity } \\
\text { (g water/g dry feed) } \\
\text { By centrifugation }\end{array}$} \\
\hline Mean & $1 \cdot 53$ & $2 \cdot 17$ & $2 \cdot 73$ & $3 \cdot 15$ & 3.57 \\
\hline $\mathbf{S E}$ & 0.05 & 0.08 & 0.04 & 0.16 & 0.04 \\
\hline \multicolumn{6}{|l|}{ By filtration } \\
\hline Mean & $2 \cdot 13$ & 2.77 & $3 \cdot 28$ & 3.56 & 4.02 \\
\hline $\mathrm{SE}$ & $0 \cdot 15$ & 0.16 & 0.04 & 0.01 & 0.03 \\
\hline
\end{tabular}

nd, not determined; NDF, neutral-detergent fibre.

displacement method described by Peterson \& Baumgardt (1971). Duplicate determinations were made on $50 \mathrm{~g}$ samples of each feed (as fed and without further grinding), using $250 \mathrm{ml}$ volumetric flasks in a water-bath at $37^{\circ}$. First, $100 \mathrm{ml}$ distilled water at $37^{\circ}$ was placed in the flask and then the $50 \mathrm{~g}$ sample of feed was added. After mixing, an additional $50 \mathrm{ml}$ water was added and the contents were allowed to equilibrate for $15 \mathrm{~min}$; last, an additional $50 \mathrm{ml}$ water was then added. After allowing $15 \mathrm{~min}$ to equilibrate, the flask was filled to volume by adding water from a burette. The total amount of water contained in the flask was subtracted from $250 \mathrm{ml}$. The density of the diet was expressed in $\mathrm{g} / \mathrm{ml}$.

The WHC of the feeds was measured using modifications of the two methods of centrifugation and filtration described by Robertson \& Eastwood (1981). For the centrifugation method $(n)$ tared centrifuge tubes $(25 \mathrm{ml})$, each containing $0.5 \mathrm{~g}$ oven-dry feed soaked for $24 \mathrm{~h}$ in distilled water, were centrifuged at $6000 \mathrm{~g}$ for $15 \mathrm{~min}$, the supernatant fraction decanted and the fresh weight of feed determined. After freeze-drying, the WHC was calculated as $\mathrm{g}$ water/g dry feed. With the filtration method $(n 3) 1 \mathrm{~g}$ samples 
Table 2. The composition, chemical analysis ( $\mathrm{g} / \mathrm{kg}$ fresh weight) and 'bulk' characteristics of the basal diet $(B)$-dried-grass-meal $(G)$ and $B$-dried-citrus pulp $(C)$ series of feeds

\begin{tabular}{|c|c|c|c|c|c|}
\hline Feed ... & B & $\begin{array}{c}\mathrm{BG}_{2} \\
(0.5 \mathrm{~B}+0.5 \mathrm{G})\end{array}$ & $\mathbf{G}$ & $\begin{array}{c}\mathrm{BC}_{2} \\
(0-5 \mathrm{~B}+0.5 \mathrm{C})\end{array}$ & C \\
\hline \multicolumn{6}{|l|}{ Ingredients (g/kg) } \\
\hline Herring meal & 180 & 90 & - & 90 & - \\
\hline Dried skimmed milk & 100 & 50 & - & 50 & - \\
\hline Micronized wheat & 680 & 340 & - & 340 & - \\
\hline Dried-grass-meal & - & 476.9 & $953 \cdot 7$ & - & - \\
\hline Dried-citrus-pulp & - & - & - & 456.7 & $913 \cdot 3$ \\
\hline Maize oil & 20 & 20 & 20 & 20 & 20 \\
\hline Lysine hydrochloride & - & $0 \cdot 1$ & 0.2 & 5.6 & $11 \cdot 3$ \\
\hline DL-Methionine & - & 0.05 & $0 \cdot 1$ & $2 \cdot 4$ & $4 \cdot 8$ \\
\hline L-Threonine & - & - & - & $2 \cdot 5$ & $5 \cdot 0$ \\
\hline Tryptophan & - & - & - & $1 \cdot 0$ & 1.9 \\
\hline Dicalcium phosphate & - & 3 & 6 & $10 \cdot 9$ & $21 \cdot 7$ \\
\hline Limestone & - & - & - & - & - \\
\hline Salt & - & - & - & 1 & 2 \\
\hline Vitamin and mineral & 20 & 20 & 20 & 20 & 20 \\
\hline Total & $1000 \cdot 0$ & $1000 \cdot 05$ & $1000-0$ & $1000 \cdot 1$ & $1000 \cdot 0$ \\
\hline \multicolumn{6}{|l|}{ Component $(\mathrm{g} / \mathrm{kg})$} \\
\hline $\begin{array}{l}\text { Digestible energy } \\
(\mathrm{MJ} / \mathrm{kg})\end{array}$ & $13 \cdot 7$ & $10 \cdot 3$ & 6.9 & $11 \cdot 7$ & $9 \cdot 8$ \\
\hline Dry matter & 884 & 877 & 887 & 886 & 861 \\
\hline Crude protein $(\mathrm{N} \times 6.25)$ & 234 & 171 & 98 & 160 & 75 \\
\hline Diethyl ether extract & 53 & 41 & 45 & 40 & 36 \\
\hline Ash & 56 & 72 & 82 & 74 & 83 \\
\hline Crude fibre & 19 & 115 & 248 & 67 & 104 \\
\hline NDF & 86 & 268 & 468 & 132 & 122 \\
\hline Organic matter digestibility & 868 & 668 & 467 & 783 & 698 \\
\hline Density $(\mathrm{g} / \mathrm{ml})$ & 1.363 & $1 \cdot 350$ & 1.296 & 1.367 & 1.433 \\
\hline \multicolumn{6}{|l|}{$\begin{array}{l}\text { Water-holding capacity } \\
\text { (g water/g dry feed) } \\
\text { By centrifugation }\end{array}$} \\
\hline Mean & 1.53 & 3.43 & $5 \cdot 30$ & 3.86 & $6 \cdot 29$ \\
\hline $\mathrm{SE}$ & 0.05 & 0.09 & 0.13 & 0.07 & 0.08 \\
\hline \multicolumn{6}{|l|}{ By filtration } \\
\hline Mean & $2 \cdot 13$ & 3.65 & $5 \cdot 19$ & $4 \cdot 30$ & 6.57 \\
\hline SE & $0 \cdot 15$ & 0.07 & 0.05 & 0.07 & $0 \cdot 10$ \\
\hline
\end{tabular}

NDF, neutral-detergent fibre.

of dry feed were soaked in distilled water ( $500 \mathrm{ml}$ for $24 \mathrm{~h}$ ). Samples were filtered through Whatman no. 2 filter paper (Whatman International Ltd, Maidstone, Kent), and the fresh weight determined. They were then freeze-dried and, hence, WHC calculated.

The digestibility measurements were conducted on another twenty-one similar entire male pigs with a mean live weight of 15.7 (SD 2.0) $\mathrm{kg}$. They were randomly allocated to the basal, the intermediate $\left(\mathrm{BW}_{2}, \mathrm{BG}_{2}\right.$ and $\left.\mathrm{BC}_{2}\right)$ or the bulky feeds $(\mathrm{W}, \mathrm{G}$ and $\mathrm{C})$ and were given $600 \mathrm{~g}$ feed $/ \mathrm{d}$ in two separate allowances. The allowance of $600 \mathrm{~g} / \mathrm{d}$ was estimated to be just below the ad lib. feed intake on the bulkiest feed. The seven feeds were supplemented with $20 \mathrm{~g}$ acid-washed sand (medium fine; BDH, Lutterworth, Leics)/ $\mathrm{kg}$ used as a marker, and re-pelleted before they were given to the pigs. After an adaptation period of $18 \mathrm{~d}$, faecal ' $\mathrm{grab}$ ' samples were collected for an additional $6 \mathrm{~d}$. 


\section{Design}

Each of the fifty-one pigs, on reaching the planned starting live weight of $12 \mathrm{~kg}$, was assigned at random, first to Expt $1(n 15)$ or to Expt $2(n 36)$ and second to the treatments (five in Expt 1 and eighteen in Expt 2) within each experiment. The only restriction used was such that the smallest possible number of littermates was on any one treatment.

Expt 1. The five treatments used, each with three pigs, were to give free and continuous access to one of the five feeds of the $\mathrm{W}$ series, i.e. $\mathrm{B}, \mathrm{BW}_{1}, \mathrm{BW}_{2}, \mathrm{BW}_{3}$ and $\mathrm{W}$, from the starting live weight to $25 \mathrm{~kg}$ live weight, at which live weight they were all slaughtered.

Expt 2. Thirty-six pigs were used with twelve pigs assigned to each of three feed series. The feeds of the three series were: $\left(B, B_{2}\right.$ and $\left.W\right),\left(B, B_{2}\right.$ and $\left.G\right)$ and $\left(B, B_{2}\right.$ and $\left.C\right)$ respectively. Each of the possible six sequences, which used each of the three feeds only once, was replicated on two pigs. There were, thus, six sequences for each series each replicated on two pigs.

The change-over design was used for two reasons: first, to reduce the effects of any consistent variation in feed intake between pigs, as it was thought that this could be large; second the design allowed the time-course of changes of feed intake following a change of feed to be measured. Initially it was intended that the pigs spend equal periods of time (14 d) on each of the three feeds but the actual times were changed to be: $9 \mathrm{~d}$ on the basal, $16 \mathrm{~d}$ on the equal parts mixture and $17 \mathrm{~d}$ on the 'bulky' feeds. This was done because it was found that a longer time was needed for the pigs to adapt to the more 'bulky' feeds. The data from the last $5 \mathrm{~d}$ of each period were used in the analysis of the results. All data were used to consider the time-courses of the changes. As the periods were of unequal length, possible effects of calendar time on intake were considered, although they were not expected to be present with the close control over temperature and day length that was exercised. The experiment lasted for $\mathbf{4 2} \mathrm{d}$ and at the end of the experiment all the pigs were slaughtered.

\section{Management and slaughter procedures}

All pigs were weighed daily during the morning and fed twice daily to minimize spillage, which was low and measured. Feed refusals were weighed daily and discarded; for wet refusals dry matter content was measured. The ambient temperature was gradually reduced from $28^{\circ}$, when the pigs were first moved, to $21^{\circ}$, when the first pig reached $12 \mathrm{~kg}$ live weight, at which level it was held constant until the end of the experiment.

On the day of slaughter the pigs were weighed and feed refusals removed early in the morning. The pigs were killed at 12.00 hours by an injection of pentobarbitol sodium (Euthatal; Rhône Merieux, Harlow, Essex). The liver, stomach, small and large intestines with the caecum were removed and weighed full, stripped of their contents and then weighed empty. Gut fill was calculated as the difference.

\section{Analysis of the results}

The results from the $\mathrm{W}$ series of feeds in Expt 1 were treated by analysis of variance, as a randomized design with feed as a factor. The results from each of the three series in Expt 2 were initially analysed separately. Subsequently, they were considered as a single design and analysed by the use of the residual maximum likelihood (REML; Robinson, 1987), with the assumption that pigs had only random effects on the outcome.

\section{RESULTS}

Feed characteristics

Of the feed characteristics measured in the present experiment, those expected to be negatively related to bulkiness were DE content, digestibility of the organic matter, and 
Table 3. Expt 1. The daily rate of feed intake, both absolute and scaled to live weight, liveweight gain and feed conversion efficiency (FCE) of pigs given access to either a basal $(B)$ or a wheat-bran-based $(W)$ feed, or their three step mixtures $\left(B W_{1}, B W_{2}, B W_{3}\right)$ from $12-25 \mathrm{~kg}$ live weight

\begin{tabular}{|c|c|c|c|c|c|c|c|}
\hline Feed $† \ldots$ & B & $\begin{array}{c}\mathrm{BW}_{1} \\
(0.75 \mathrm{~B}+0.25 \mathrm{~W})\end{array}$ & $\begin{array}{c}\mathrm{BW}_{8} \\
(0.5 \mathrm{~B}+0.5 \mathrm{~W})\end{array}$ & $\begin{array}{c}\mathrm{BW}_{3} \\
(0.25 \mathrm{~B}+0.75 \mathrm{~W})\end{array}$ & W & SED & $\begin{array}{l}\text { Statistical } \\
\text { significance } \\
\text { of feed }\end{array}$ \\
\hline $\begin{array}{l}\text { Feed intake }(g / d) \\
\text { Scaled feed intake } \\
(\mathrm{g} / \mathrm{kg} \text { per } \mathrm{d})\end{array}$ & 905 & 957 & 1040 & 908 & 875 & 60 & NS \\
\hline First $6 \mathrm{~kg}$ of feed & 51 & 53 & 59 & 39 & 31 & $3 \cdot 4$ & $* * *$ \\
\hline Last $6 \mathrm{~kg}$ of feed & 49 & 48 & 54 & 60 & 55 & $3 \cdot 0$ & $*$ \\
\hline Live-wt gain $(\mathrm{g} / \mathrm{d})$ & 733 & 710 & 670 & 449 & 355 & 31 & $* * *$ \\
\hline $\begin{array}{l}\mathrm{FCE} \text { (g gain } / \mathrm{kg} \\
\text { intake) }\end{array}$ & 811 & 743 & 645 & 498 & 406 & 28 & $* * *$ \\
\hline
\end{tabular}

NS, not significant; SED, standard error of difference.

$* P<0.05, * * P<0.001$.

† For details of feeds and procedures, see Table 1 and pp. 192-195.

density (a unit weight of feed yields less volume as density increases) and those positively related to bulkiness were fibre content (in terms of both CF and NDF) and WHC. Of the three 'bulky' feeds used, $G$ had the lowest $\mathrm{DE}(6.9 \mathrm{MJ} / \mathrm{kg}$ feed) and the highest $\mathrm{CF}$ and NDF contents (248 and $468 \mathrm{~g} / \mathrm{kg}$ fresh feed, respectively), $\mathrm{G}$ and $\mathrm{W}$ had the lowest densities $(1.296 \mathrm{~g} / \mathrm{ml})$ and $\mathrm{C}$ had the greatest WHC by both methods used, with values of $6.29 \mathrm{~g}$ water/g dry feed by centrifugation and $6.57 \mathrm{~g}$ water/g dry feed by filtration. Across the nine feeds used the two methods of measuring the WHC were very highly correlated $(r+0.993)$ and one could be predicted from the other with high precision:

$$
\begin{array}{rlr}
\text { WHC }_{\mathrm{c}}= & -0.830+1.11 \mathrm{WHC}_{\mathrm{r}} & \text { residual SD (RSD) } 0.182, \\
& (\mathrm{SE} 0.210)(\mathrm{SE} 0.0487) & \\
\mathrm{WHC}_{\mathrm{t}}= & 0.787+0.886 \mathrm{WHC}_{\mathrm{c}} & \text { (RSD) } 0.162, \\
& (\mathrm{SE} 0.148)(\mathrm{SE} 0.0388) &
\end{array}
$$

where $\mathrm{WHC}_{\mathrm{c}}$ and $\mathrm{WHC}_{\mathrm{f}}$ are the $\mathrm{WHC}$ determinations by centrifugation and filtration respectively. The errors of the WHC estimations by both methods were very low.

Expt 1. Wheat-bran series given from 12 to $25 \mathrm{~kg}$ live weight

The results from the $W$ series of feeds $\left(B, B W_{1}, B W_{2}, B W_{3}\right.$ and $W$ ) given to pigs continuously from 12 to $25 \mathrm{~kg}$ live weight are shown in Table 3 . The effect of the progressive dilution of $B$ by $W$ on daily feed intake was quadratic $(P<0.05)$, with animals achieving the highest feed intake on the feed $\mathrm{BW}_{2}$. The daily live-weight gain and feed conversion efficiency (FCE, expressed as g gain $/ \mathrm{kg}$ feed intake) both decreased significantly as B was progressively diluted with $\mathrm{W}$ (from B to W; $P<0.001$ ).

The effects of treatment on intake were examined further by considering the rate of intake in relation to live weight for the first $6 \mathrm{~kg}$ feed eaten from the starting live weight of $12 \mathrm{~kg}$. The long-term effects were examined by considering the rate of intake in relation to live weight for the final $6 \mathrm{~kg}$ feed eaten to achieve the finishing live weight of $25 \mathrm{~kg}$. The $6 \mathrm{~kg}$ quantities were chosen so that the two sub-periods had no data in common for any pig. It was found (Fig. 1) that progressive dilution of B with $W$ had different effects on feed 


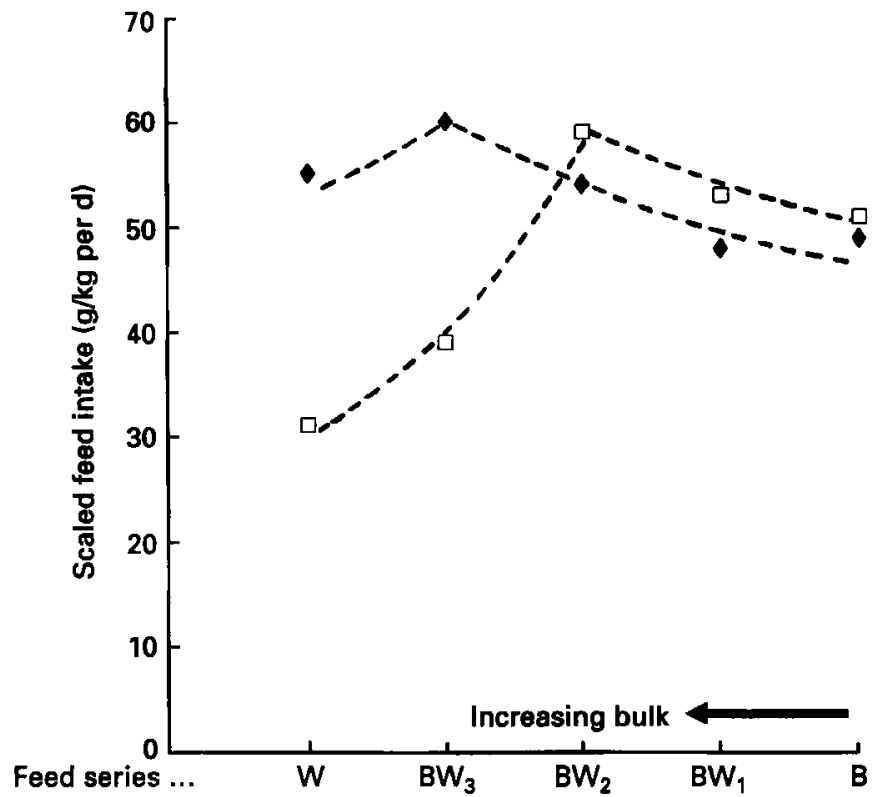

Fig. 1. Expt 1. The scaled feed intake ( $\mathrm{g} / \mathrm{kg}$ live weight per d) for the first $(\diamond)$ and last $(\square) 6 \mathrm{~kg}$ feed consumed by pigs given access to a wheat-bran series of feeds (from basal feed $B$ to one based almost entirely on wheat bran (W). For details of experimental feeds, see p. 192 and Table 1.

Table 4. Expt 1. The weights of the gastrointestinal tract sections and gut-fill of pigs given access to either a basal $(B)$ or a wheat-bran-based $(W)$ feed, or their three step mixtures $\left(B W_{1}\right.$, $B W_{2}, B W_{3}$ ) from $12-25 \mathrm{~kg}$ live weight, and slaughtered at $25 \mathrm{~kg}$ live weight

\begin{tabular}{|c|c|c|c|c|c|c|c|}
\hline Feed ... & $\mathbf{B}$ & $\begin{array}{c}\mathrm{BW}_{1} \\
(0.75 \mathrm{~B}+ \\
0.25 \mathrm{~W})\end{array}$ & $\begin{array}{c}\mathrm{BW}_{2} \\
\left(0.5 \mathrm{~B}_{+}\right. \\
0.5 \mathrm{~W})\end{array}$ & $\begin{array}{c}\mathrm{BW}_{3} \\
(0.25 \mathrm{~B}+ \\
0.75 \mathrm{~W})\end{array}$ & $\mathbf{w}$ & SED & $\begin{array}{l}\text { Statistical } \\
\text { significance } \\
\text { of feed }\end{array}$ \\
\hline Stomach wt (g) & 173 & 193 & 227 & 280 & 247 & 13 & $* * *$ \\
\hline Small intestine wt (g) & 1033 & 873 & 820 & 913 & 860 & 63 & $*$ \\
\hline Large intestine wt (g) & 420 & 440 & 507 & 580 & 673 & 44 & $* * *$ \\
\hline Caecum wt (g) & 63 & 47 & 70 & 70 & 70 & 7.9 & NS \\
\hline Mesentery wt (g) & 353 & 300 & 340 & 387 & 413 & 30 & $*$ \\
\hline Gut fill (g) & 1130 & 1133 & 1837 & 2410 & 3117 & 264 & $* * *$ \\
\hline Gut fill: live wt $(\mathrm{g} / \mathrm{kg})$ & 44 & 44 & 73 & 96 & 126 & 11 & **** \\
\hline \multirow{2}{*}{$\begin{array}{l}\text { Gut fill: feed intake in } \\
\text { last } 5 \mathrm{~d}(\mathrm{~g} / \mathrm{kg})\end{array}$} & & & & & & & \\
\hline & 1.00 & 0.98 & 1.47 & 1.72 & 2.35 & 0.24 & *** \\
\hline
\end{tabular}

SED, standard error of difference; NS, not significant.

$* P<0.05, * * P<0.01, * * * P<0.001$.

intake for the two periods. For the first $6 \mathrm{~kg}$ consumed, scaled feed intake behaved in a manner similar to the overall daily feed intake with the highest feed intake achieved with feed $\mathrm{BW}_{2}$. However, the scaled feed intake for the last $6 \mathrm{~kg}$ feed consumed continued to increase up to a higher dilution ( $f e e d \mathrm{BW}_{3}$ ) and declined only when feed $\mathrm{W}$ was given.

The weights of the components of the gastrointestinal tract and of the gut fill of the pigs given access to the $W$ series and slaughtered at $25 \mathrm{~kg}$ live weight are shown in Table 4. The progressive increase in $\mathrm{W}$ content of the feed resulted in significant increases $(P<0.05)$ in the weights of gut fill, stomach, mesentery and large intestine, and a significant decrease in 

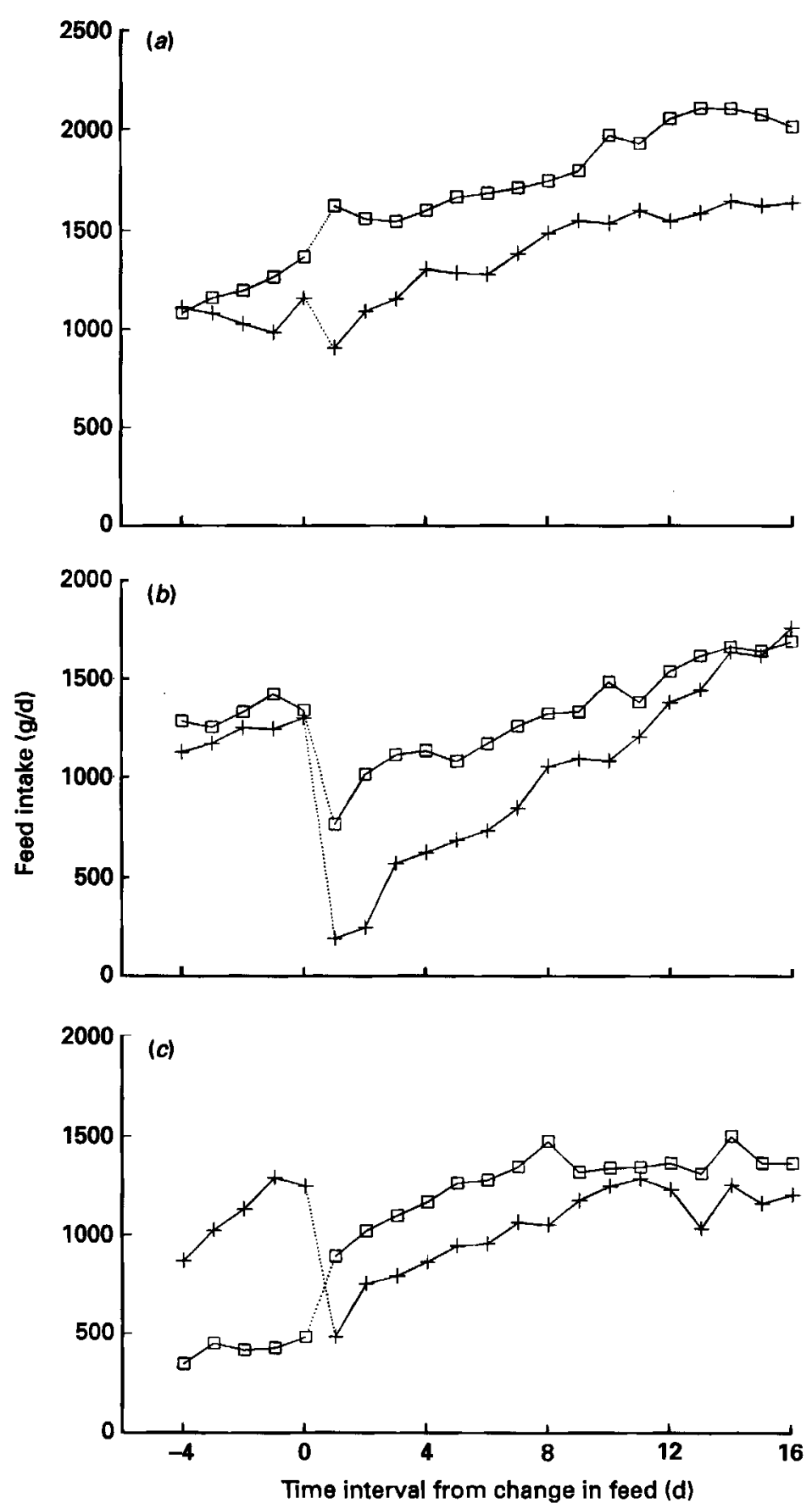

Fig. 2. For legend see facing page. 

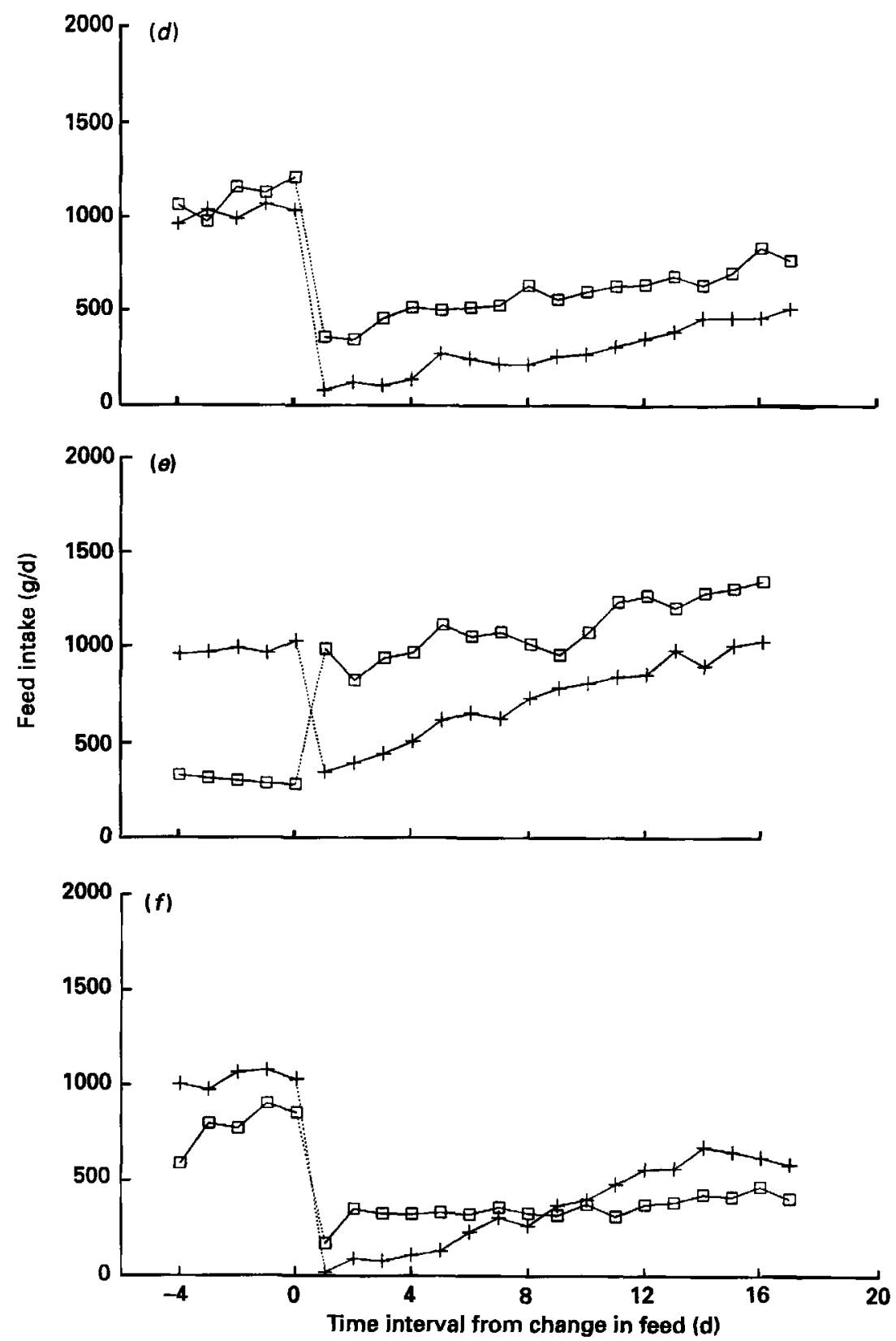

Fig. 2. Expt 2. The time-course of daily feed intake $(\mathrm{g} / \mathrm{d})$ following a change of feed from the basal $(+)$ or the bulkier feeds ( $\square$, for the wheat bran (W) series: (a) B to BW $\mathrm{BW}_{2}(+)$, W to $\mathrm{BW}_{2}(\square)$; (b) B to W $(+)$, BW $\mathrm{BW}_{2}$ to

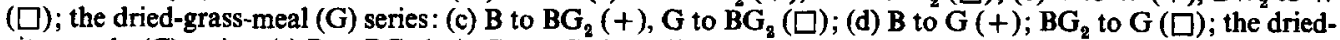
citrus-pulp (C) series: (e) B to $\mathrm{BC}_{2}(+), C$ to $\mathrm{BC}_{2}(\square)$; (f) B to C (+), BC $\mathrm{C}_{2}$ to $\mathrm{C}(\square)$. Points represent means for four-values. For details of experimental feeds, see p. 192 and Tables 1 and 2. 


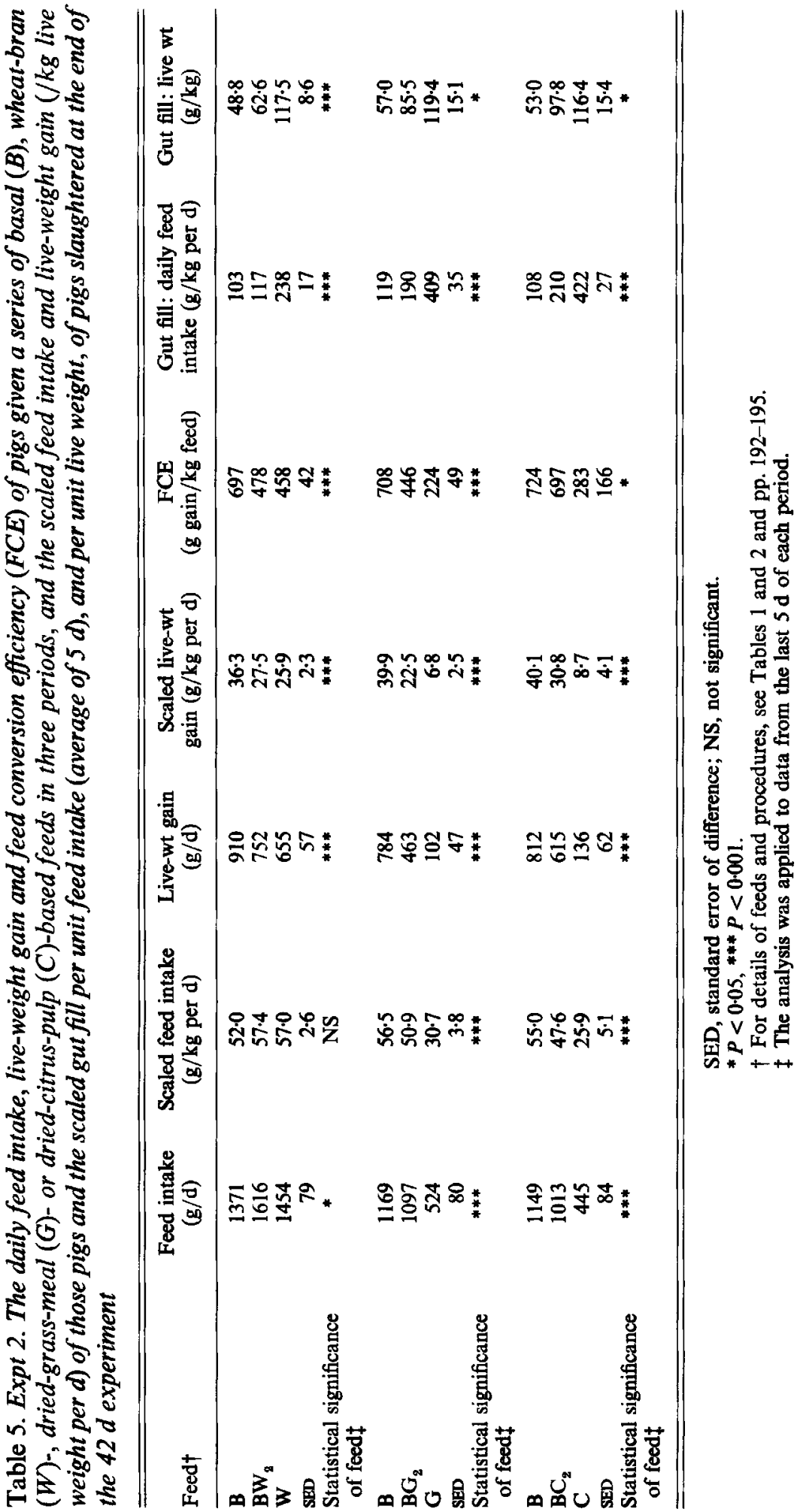


Table 6. Expt 2. The intercepts (a) and the regression coefficients* of feed intake $(F I ; g / d)$ v. live weight $(\mathrm{LW} ; \mathrm{kg})$ of pigs given a series of basal $(B)$, wheat-bran $(W)$-, dried-grass-meal $(G)$ - or dried-citrus-pulp $(C)$-based feeds in three periods, using data for the final 5 d of each period

(Mean values with their standard errors)

\begin{tabular}{|c|c|c|c|c|c|c|c|c|c|}
\hline \multirow[b]{2}{*}{ Feed $\dagger$} & \multirow[b]{2}{*}{$n$} & \multicolumn{2}{|c|}{$a(\mathrm{~g} / \mathrm{kg}$ per $\mathrm{d})$} & \multicolumn{2}{|c|}{$b_{1}(\mathrm{~g} / \mathrm{kg} \text { per d })^{1}$} & \multirow[b]{2}{*}{ RSD } & \multicolumn{2}{|c|}{$b_{2}(g / k g \text { per d })^{1}$} & \multirow[b]{2}{*}{ RSD } \\
\hline & & Mean & $\mathbf{S E}$ & Mean & SE & & Mean & SE & \\
\hline $\begin{array}{l}\text { B } \\
\mathrm{BW}_{2} \\
\mathrm{~W} \\
\mathrm{BG}_{2} \\
\mathrm{G}_{2} \\
\mathrm{BC}_{2} \\
\mathrm{C}\end{array}$ & $\begin{array}{l}36 \\
12 \\
12 \\
12 \\
12 \\
12 \\
12\end{array}$ & $\begin{array}{r}205 \\
89 \\
234 \\
-188 \\
32 \\
-257 \\
-200\end{array}$ & $\begin{array}{r}95 \\
327 \\
156 \\
277 \\
126 \\
264 \\
235\end{array}$ & $\begin{array}{l}44 \cdot 8 \\
53.9 \\
46.9 \\
60.5 \\
28.6 \\
60 \cdot 7 \\
39 \cdot 4\end{array}$ & $\begin{array}{r}4 \cdot 0 \\
11 \cdot 2 \\
5 \cdot 7 \\
12 \cdot 7 \\
7 \cdot 0 \\
12 \cdot 3 \\
13 \cdot 8\end{array}$ & $\begin{array}{l}156 \\
294 \\
173 \\
210 \\
119 \\
204 \\
225\end{array}$ & $\begin{array}{l}53 \cdot 0 \\
56 \cdot 8 \\
55 \cdot 0 \\
52 \cdot 1 \\
30 \cdot 3 \\
49 \cdot 0 \\
28 \cdot 1\end{array}$ & $\begin{array}{l}1.1 \\
2.8 \\
1.9 \\
2 \cdot 7 \\
1.8 \\
2.7 \\
3 \cdot 8\end{array}$ & $\begin{array}{l}164 \\
282 \\
182 \\
205 \\
114 \\
203 \\
222\end{array}$ \\
\hline
\end{tabular}

RSD, residual standard deviation.

* The coefficients $a$ and $b_{1}$ are calculated from the equation $\mathrm{FI}(\mathrm{g} / \mathrm{kg} \mathrm{per} \mathrm{d})=a+b_{1} \mathrm{LW}$ and $b_{2}$ from equation FI $(\mathrm{g} / \mathrm{kg}$ per $\mathrm{d})=b_{2}$ LW.

$\dagger$ For details of feeds and procedures, see Table 1 and pp. 192-195.

the weight of the small intestine. The increases in the weights of the organs and gut-fill weights were essentially linear $(P<0.05)$.

Expt 2. Series of three feeds offered in change-over designs

Time-course of changes in feed intake. The time-course of daily feed intake following a change of feed are shown in Fig. 2. Intakes of the bulkiest feeds (W, G and C) were greater when the preceding feed was the intermediate feed $\left(\mathrm{BW}_{2}, \mathrm{BG}_{2}\right.$ or $\left.\mathrm{BC}_{2}\right)$ than when it was $\mathrm{B}$. Similarly, the intakes of the intermediate feeds were initially greater when they followed the bulkiest feeds rather than B. The effect of the previous feed tended to decrease with time. The intakes of B were not affected by the feed given previously (values not shown in Fig. 2).

Results from the final 5 d of each period of the change-over designs. The daily feed intake, live-weight gain and FCE of pigs in the three series are shown in Table 5. As expected, the effects of period on the previous measurements were large and highly significant, but, as was not expected, the variation between pigs was small and not significant. The dilution of feed B, with either $\mathbf{C}$ or $\mathbf{G}$, was associated with a significant reduction in the daily feed intake and, thus, the highest feed intake in each series was achieved on feed $B$. However, the highest feed intake on the $\mathrm{W}$ series was achieved on $\mathrm{BW}_{2}(P<0.05)$. Daily live-weight gain and FCE both decreased significantly $(P<0.001)$ in all three series as the basal feed was diluted by the bulky material.

The pigs increased in live weight with time and, hence, with the successive periods of the experiment. To find the appropriate scaling of feed intake $(\mathrm{g} / \mathrm{d})$ to live weight $(\mathrm{kg} / \mathrm{d})$, feed intake was regressed on live weight, using all of the data from each of the seven feeds. As shown in Table 6, the intercepts for the six more bulky feeds were not significantly different from zero with three positive and three negative. The proposition that, within the range of live weights occurring, feed intake was directly proportional to live weight was not rejected and a scaled rate of intake was calculated as $\mathrm{g}$ feed intake/ $\mathrm{kg}$ live weight per $\mathrm{d}$. The regression coefficients, with the intercept suppressed, are given in Table 6 . 
For $B$ the intercept of the regression of feed intake $v$. live weight was significant $(P<$ 0.05 ). There is no a priori reason for the scaling of feed intake to live weight to be the same for feeds that limit intake by their bulk and for those that do not, and so this discrepancy was not surprising. However, for consistency, the intakes of B were also scaled directly to live weight.

The scaled intakes and live weight gains are shown in Table 5. The scaled intake on $\mathrm{BG}_{2}$ was 0.90 , and on $\mathrm{BC}_{2}, 0.87$ of that on $\mathrm{B}$, although these reductions just failed to be significant. They contrast with the scaled intake on $\mathrm{BW}_{2}$ being $1 \cdot 10$ of that on $\mathrm{B}$. The scaled intake on $\mathrm{G}$ was 0.54 and on $\mathrm{C} 0.47$ of that on $\mathrm{B}$, with both reductions being highly significant, while the scaled intake on $W$ was 1.10 of that on $B$, although the increase was not significant. The scaled live-weight gains showed severe reductions on $\mathrm{G}$ and $\mathrm{C}$ with smaller, but still significant $(P<0.05)$, effects on $\mathrm{BG}_{2}, \mathrm{BC}_{2}, \mathrm{BW}_{2}$ and $\mathrm{W}$. These effects included short-term changes in gut fill which were not measured but almost certainly occurred.

The gut fill was expressed both per unit daily feed intake, as measured over the final $5 \mathrm{~d}$ before slaughter, and per unit live weight (Table 5). In the first case it increased very considerably and progressively with dilution, with the $\mathbf{G}$ and $\mathrm{C}$ series behaving similarly and the $\mathrm{W}$ series having a lesser effect $(P<0.01)$. When expressed per unit live weight the values for the obviously limiting feeds $W, B_{2}, G, B_{2}$ and $C$ were similar and not significantly different with an overall mean ( $n$ 20) of 107 (SE 3.8) g/ kg live weight.

\section{DISCUSSION}

The effects, in Expt 1, of diluting the highly digestible B with the poorly digested bulky feed W, were, at least qualitatively, those expected (see Fig. 1 of the Appendix) when considered over the whole live-weight range of $12-25 \mathrm{~kg}$. On the most dilute feeds, $\mathrm{BW}_{3}$ and $\mathrm{W}$, there was a clear reduction in feed intake compared with the intermediate feed $\mathrm{BW}_{2}$, with intake on this feed being greater than that on B. When, however, the intakes were considered separately for the earlier and later parts of the experimental period there were clearly large effects of time, which could be seen as being due to accommodation to the bulkier feeds, $\mathrm{BW}_{3}$ and $\mathrm{W}$. While the scaled feed intake hardly changed with time on the experiment for feeds $\mathrm{B}, \mathrm{BW}_{1}$ and $\mathrm{BW}_{2}$, it increased 1.54 times for $\mathrm{BW}_{3}$ and 1.77 times for $\mathrm{W}$, between the earlier and the later parts of the experimental period.

The apparent accommodation to the bulkier feeds with time is reflected in the changes in the gastrointestinal tracts of the pigs slaughtered at $25 \mathrm{~kg}$ live weight. The weights of the stomach, large intestine and caecum increased with increasing $W$ content in the diet, whereas that of the small intestine decreased. It has been recognized that the weight and volume of the whole gut, and of particular sections of it, tend to increase in animals on bulky feeds (e.g. for pigs Low, 1985, for poultry Savory, 1992). These changes are the direct effect of the adaptation to the increasing gut fill or to the involvement of parts of the gut in fibre digestion.

The importance of the adaptation of an animal fed on bulky feeds, and its effect on intake, were also clearly observed in Expt 2 (Fig. 2). The pigs which had had access to a bulkier feed in the previous period had, at least initially, higher intakes of the bulky feed. This was the case for all three series of feeds. The carry-over effects on intake, particularly when scaled to live weight, decreased with time in such a way that scaled intakes in the final $5 \mathrm{~d}$ of each period were not affected by the treatment imposed in the previous period. The effects of a feed on the weights of the parts of the gastrointestinal tract of the pigs slaughtered at the end of the $\mathbf{4 2} \mathrm{d}$ experimental period (not detailed in the Results section) tended to be similar to those observed in the pigs from the W series in Expt 1 . The fact that 
there were no carry-over effects of the feed offered in the previous period on the weights of the parts of the gastrointestinal tract probably reflects the experimental design where pigs were given more time to adapt to the bulkier feeds (16 or $17 \mathrm{~d}$ ) than to B. Other workers (e.g. Owen \& Ridgman, 1968) have also found that a 2-week period was sufficient for the gastrointestinal tract to adapt to fibrous feeds. Last, the fact that weight of gut fill: live weight was approximately constant for the feeds that were obviously limiting intake probably reflects the maximum capacity of the gastrointestinal tract per unit live weight.

A change-over design was adopted in Expt 2 because we expected that there would be considerable differences between individual pigs in the intakes of feeds which were limiting intake through their bulk. However, this turned out not to be the case, with the effect of animal in the statistical analyses being trivial and never significant. The value of the design is seen in the data presented in Fig. 2. Both Expts 1 and 2 show clearly that the effects of time-period (adaptation) on bulky feeds need to be considered when attempting to measure or predict the rates of intake on different bulky feeds.

Although only three sources of bulk were used, it was clear that the effects on feed intake could not be accounted for simply in terms of differences in digestibility, a view already asserted in the Introduction. $\mathrm{C}$ was much more digestible than the other two bulky feeds used but the pigs ate no more of it than of the feeds in the $G$ series, and less of it than of the feeds in the W series. Similar arguments apply to three of the other measurements made (density and the crude fibre and NDF contents) since these qualities could not account for the effects on feed intake. However, the fifth measurement made, that of the WHC of the feeds, seemed to account satisfactorily for the effects on intake of those feeds which appeared to be limiting intake through their bulk (see Fig. 3, where the scaled feed intake $v$. $\mathrm{WHC}_{\mathrm{c}}$ is plotted). The relationship between the scaled feed intake $(\mathrm{g} / \mathrm{kd}$ per $\mathrm{d})$ and the reciprocal of $\mathrm{WHC}_{c}$, calculated using individual pig and period data, was essentially linear:

$$
\mathrm{SFI}=\underset{(\mathrm{SE} 5 \cdot 00)}{1.74}+\underset{(\mathrm{SE} 18.8)}{167.7}\left(\frac{1}{\mathrm{WHC}_{\mathrm{c}}}\right) \quad r^{2} 0.533, \text { RSD 10.9, }
$$

where SFI is scaled feed intake. The $\mathrm{WHC}_{\mathrm{c}}$ (measured as $\mathrm{g}$ water/g dry feed) was related to fresh feed intake rather than dried feed intake, because the dry matter of all feeds used was very similar at close to $880 \mathrm{~g} / \mathrm{kg}$ fresh feed, and throughout the experiment fresh feed intake was recorded. Given that the intercept of the equation 3 was not significantly different from zero, the relationship could be as well represented by:

$$
\mathrm{SFI}=\underset{(\mathrm{SE} \mathrm{4.78)}}{174-1} \times\left(\frac{1}{\mathrm{WHC}_{\mathrm{c}}}\right) \quad \text { RSD 10.8, }
$$

which is equivalent to saying that the quantity $\left(\mathrm{SFI} \times \mathrm{WHC}_{\mathrm{c}}\right)$ is constant at the value of $174 \mathrm{~g} / \mathrm{kg}$ per $\mathrm{d}$ which can be assumed to be the limit of the pigs for WHC. The line of this equation is shown in Fig. 3. The equation was re-estimated with intake expressed as the scaled dry matter intake (SFID) in order to be consistent with the $\mathrm{WHC}_{c}$ values being expressed on a dry matter basis:

$$
\operatorname{SFID}(\mathrm{g} / \mathrm{kg} \text { per } \mathrm{d})=\underset{(\operatorname{SE~4} \cdot 18)}{153 \cdot 0} \times\left(\frac{1}{\mathrm{WHC}_{\mathrm{c}}}\right) \quad \text { RSD 9.5. }
$$

The WHC of the feeds describes that property of the fibre of the feed, and more specifically the property of its non-starch polysaccharides, to trap water, swell and form gels with high water contents (Eastwood, 1973). This ability is relevant to specific polysaccharides such as pectins (Bertin et al. 1988) and also depends on the method of fibre preparation (Eastwood et al. 1983). The gel formed between the fibre and the water could act as a bulk-limiting 


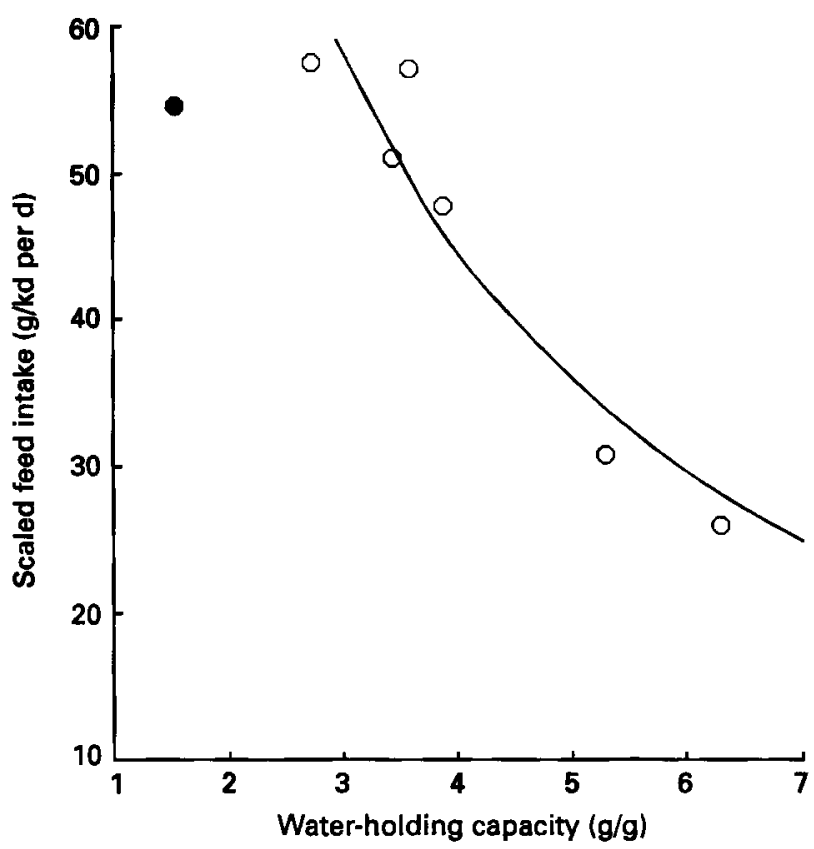

Fig. 3. Expt 2. The scaled feed intake (SFI; g/kg live weight per d) on the seven experimental feeds $v$. their waterholding capacity estimated by centrifugation $\left(\mathrm{WHC}_{\mathrm{c}} ; \mathrm{g}\right.$ water $/ \mathrm{g}$ dry feed). The basal and, therefore, non-limiting feed is shown by (O). The line shown is that for SFI $(\mathrm{g} / \mathrm{kg}$ per $\mathrm{d})=174\left(1 / \mathrm{WHC}_{\mathrm{e}}\right)$. For details of experimental feeds, see p. 192 and Tables 1 and 2.

factor at various parts of the gastrointestinal tract. These parts may include the stomach, when water intake accompanies the consumption of dry feed, and lower parts of the gut where either the WHC of the feeds is further increased by the presence of various anions (Bertin et al. 1988), or where water is retained throughout its passage through the gut to increase the weight of the faeces produced (Eastwood et al. 1983).

For the bulky feeds used the two measurements of the WHC, obtained by centrifugation and filtration, were highly correlated and, therefore, could be seen as measurements of the same thing since one could be accurately predicted from the other. For the bulky materials used the WHC estimation by filtration gave consistently higher values than those by the centrifugation method. The estimate from centrifugation was preferred in the relationships of equations 3 and 4 because it gave a slightly better fit to the data.

Thus, the WHC of the feeds fulfilled one of the experimental objectives: to identify a property of 'bulky' feeds which might be responsible for limiting their intake. We recognize the limitations of the present experiment since only three bulky materials were used and, therefore, the stated idea needs to be further tested across a wide range of bulky materials that limit feed intake and have a range of WHC, or by diluting a basal feed with a bulky material of known and high WHC, such as pectin, and measuring the effects of the dilution on the rate of feed intake.

This work was supported in part by the Scottish Office and in part by BOCM Pauls Ltd. The authors would like to acknowledge the help of Drs C. A. Morgan and A. J. Taylor with the formulation of the feeds and the technical assistance of A. MacAndrew, J. Fraser and D. H. Anderson. The REML analysis was proposed by G. W. Horgan of the Scottish Agricultural Statistics Service. 


\section{REFERENCES}

Agricultural Research Council (1981). The Nutrient Requirements of Pigs. Slough: Commonwealth Agricultural Bureaux.

Bertin, C., Rouau, X. \& Thibault, J. F. (1988). Structure and properties of sugar beet fibres. Journal of the Science of Food and Agriculture 44, 15-29.

Brouns, F., Edwards, S. A. \& English, P. R. (1991). Fibrous raw materials in sow diets. Animal Production 52, 598.

Conrad, H. R., Pratt, A. D. \& Hibbs, J. W. (1964). Regulation of feed intake in dairy cows. I. Change in importance of physical and physiological factors with increasing digestibility. Journal of Dairy Science 47, 54-62.

Eastwood, M. A. (1973). Vegetable fibre: its physical properties. Proceedings of the Nutrition Society 32, $137-143$.

Eastwood, M. A., Robertson, J. A., Brydon, W. G. \& MacDonald, D. (1983). Measurement of water-holding properties of fibre and their faecal bulking ability in man. British Journal of Nutrition 50, 539-547.

Emmans, G. C. (1994). Effective energy: a concept of energy utilization applied across species. British Journal of Nutrition 71, 801-821.

Emmans, G. C. \& Fisher, C. (1986). Problems in nutritional theory. In Nutrient Requirements of Poultry and Nutrition Research. Poultry Symposium no. 19, pp. 9-30 [C. Fisher and K. N. Boorman, editors]. London: Butterworths.

Lehmann, F. (1941). Die Lehre von Ballast (The lesson of ballast). Zeitschrift für Tierernährung und Futtermittelkunde 5, 155-173.

Low, A. G. (1985). Role of dietary fibre in pig diets. In Recent Advances in Animal Nutrition - 1985, pp. 87-112 [W. Haresign and D. J. A. Cole, editors]. London: Butterworths.

Mraz, F. R., Boucher, R. V. \& McCartney, M. G. (1957). The influence of the energy: volume ratio on growth responses in chickens. Poultry Science 36, 1217-1221.

Owen, J. B. \& Ridgman, W. J. (1967). The effect of dietary energy content on the voluntary intake of pigs. Animal Production 9, 107-114.

Owen, J. B. \& Ridgman, W. J. (1968). Further studies of the effect of dietary energy content on the voluntary intake of pigs. Animal Production 10, 85-91.

Peterson, A. D. \& Baumgardt, B. R. (1971). Food and energy intake of rats fed diets varying in energy concentration and density. Journal of Nutrition 101, 1057-1068.

Robertson, J. A. \& Eastwood, M. A. (1981). A method to measure the water-holding properties of dietary fibre using suction pressure. British Journal of Nutrition 46, 247-255.

Robinson, D. L. (1987). Estimation and use of variance components. The Statistician 36, 3-14.

Roan, S.-W. (1991). Bio-economic models for the simulation of the production and management of the growing pigs and sows. PhD Thesis, University of Edinburgh.

Savory, C. J. (1992). Gastrointestinal morphology and absorption of monosacharides in fowls conditioned to different types and levels of dietary fibre. British Journal of Nutrition 67, 77-89.

Van Soest, P. J. (1963). Use of detergents in the analysis of fibrous feeds. II. A rapid method for the determination of fiber and lignin. Journal of the Association of Official Agricultural Chemists 46, 825-828.

Whittemore, C. T. (1983). Development of recommended energy and protein allowances for growing pigs. Agricultural Systems 11, 159-186.

\section{A P PENDIX}

For simplicity only the organic matter of the feed eaten (OMI) is assumed to yield both resources and bulk to the animal. The only resource considered is energy. These restrictions can easily be relaxed and the argument extended to deal with the inorganic matter of the feed and with other resources.

OMI $(\mathrm{kg} / \mathrm{d})$ consists of two portions: that which is digested and that which is not, with the distinction between truly and apparently digested being ignored. The proportion of the organic matter that is digested is $D$.

The digested organic matter eaten (DOMI; $\mathrm{kg} / \mathrm{d}$ ) is the product of D and OMI. D yields $e_{d}$ MJ of energy and $b_{d}$ units of bulk $/ \mathrm{kg}$. The organic matter that is not digested yields $e_{u} \mathrm{MJ}$ of energy and $b_{u}$ units of bulk/ $\mathrm{kg}$ (the value of $e_{u}$ may be negative). The intake of energy, assumed for simplicity to be the first-limiting feed resource (RI; MJ/d) and the intake of bulk (BI; units/d) are given by:

$$
\begin{aligned}
& R I=\operatorname{OMI}\left(D \times e_{d}+e_{u}(1-D)\right), \\
& B I=\operatorname{OMI}\left(D \times b_{d}+b_{u}(1-D)\right) .
\end{aligned}
$$

The animal is assumed to have a requirement for energy of ERQ (assumed, for example, 


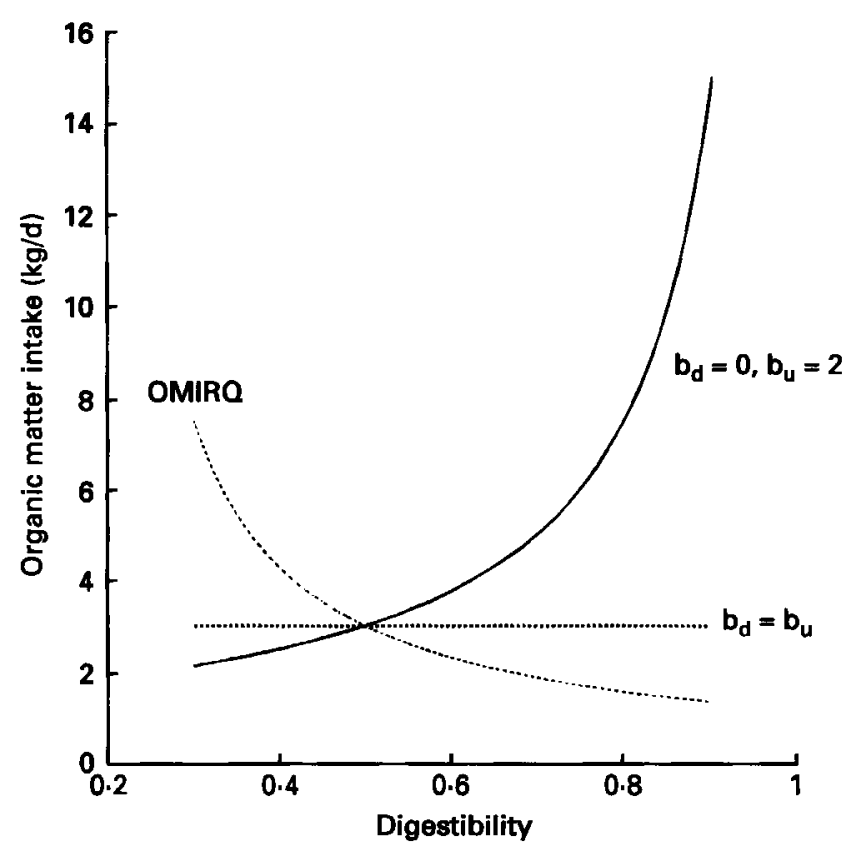

Fig. A 1. The organic matter intake (OMI; kg/d) on a feed with a critical digestibility (proportion of organic matter digested) of 0.5. (--), Organic matter that the animal has to eat in order to meet its requirements for energy (OMIRQ); (...), OMI when both the digested and undigested organic matter yield the same units of bulk $\left(b_{d}\right.$ and $b_{u}$ respectively have 1 unit of bulk/kg); (-), OMI when $b_{d}=0$ and $b_{u}=2$ units of bulk/kg.

to be $22.8 \mathrm{MJ} / \mathrm{d}$ ) and a capacity for bulk of BCAP (assumed, for example, to be 3.0 units/d). The digested organic matter, for example, is assumed to comprise 0.25 protein, 0.10 lipid and, hence, 0.65 carbohydrate and $e_{\mathrm{d}} 19 \mathrm{MJ} / \mathrm{kg}$. The undigested organic matter is assumed to have $e_{u}-3.8 \mathrm{MJ} / \mathrm{kg}$. The energy values come from Emmans (1994). The rate at which the animal needs to eat organic matter in order to just meet its requirement for energy (OMIRQ; $\mathrm{kg} / \mathrm{d}$ ) is given by:

$$
\text { OMIRQ }=E R Q /(22 \cdot 8 D-3 \cdot 8) \text {. }
$$

It is assumed that as D decreases so OMI will increase in such a way that OMI $=$ OMIRQ until some critical level of $D\left(D^{*}\right)$ is reached at which the animal's capacity for bulk is attained. For $\mathrm{D}<\mathrm{D}^{*}$ the level of OMI will be such that the animal's intake of bulk is BCAP units/d.

If it is assumed that $b_{a}=b_{u}$ then all organic matter eaten has the same capacity for filling the animal. As an example, assume that $b_{d}$, and hence $b_{\mathfrak{u}}=1$. The value of $D^{*}$ will then be 0.5 and the relationship between intake and D will be as shown in Fig. A 1. Another possible assumption is that $b_{d}=0$ and that $b_{u}$ is positive, with the value 2.0 taken here as an example so that $D^{*}$ is again $0 \cdot 5$. On this assumption the relationship will be as in Fig. A1.

The assumption that $b_{d}=0$ is a strong one and it is safer to assume that it is a positive number which can be fixed $a b_{d}=1$ with $b_{u}$ then being set on this scale. The effect of steadily increasing the value of $b_{u}$ from 2 to 4 to 8 is shown in Fig. A2; the effects on the value of $D^{*}$ can be seen. It may be that differences in the filling properties of different feeds can be accounted for by their behaving as if they had different values of $b_{u}$. 


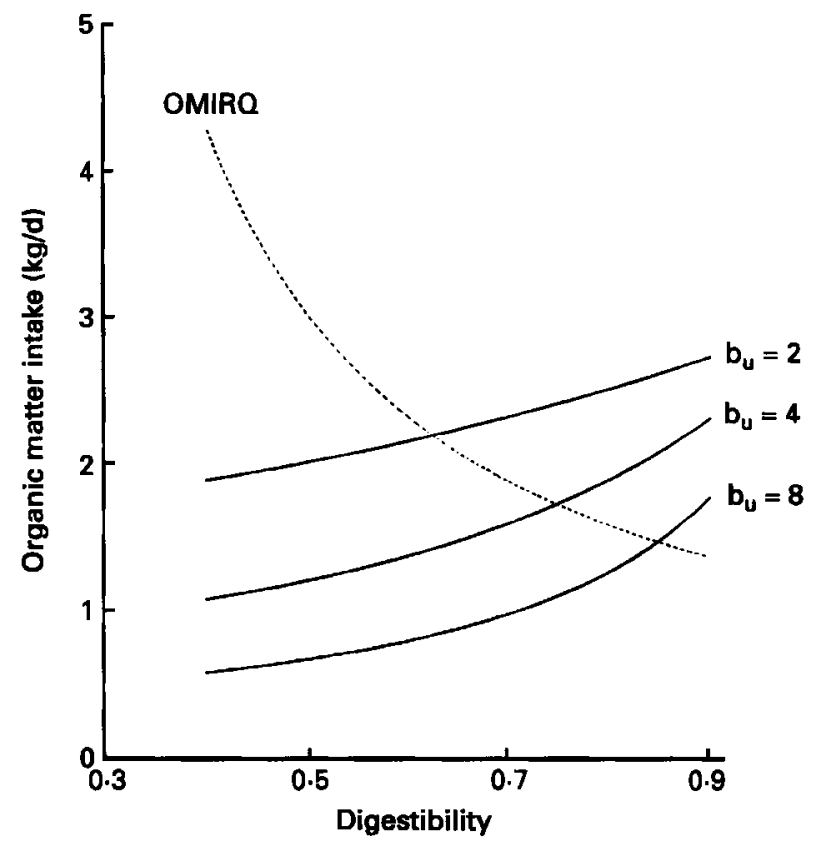

Fig. A2. The organic matter intake (OMI; kg/d) on feeds with various undigested organic matter bulk yields (units of bulk $/ \mathrm{kg} ; \longrightarrow$ ) and the organic matter that the animal has to eat in order to meet its requirements for energy (OMIRQ; ---). The points where OMI intersect OMIRQ are the critical digestibilities for these feeds.

\section{REFERENCE}

Emmans, G. C. (1994). Effective energy : a concept of energy utilization applied across species. British Journal of Nutrition 71, 801-821. 